\title{
Making sense of theoretical and conceptual frameworks \\ A C.O.S.T.A. Research Coaching Tool
}

Presented by King Costa (PhD)

\section{www.vleresearch.net. costak@researchglobal.net}

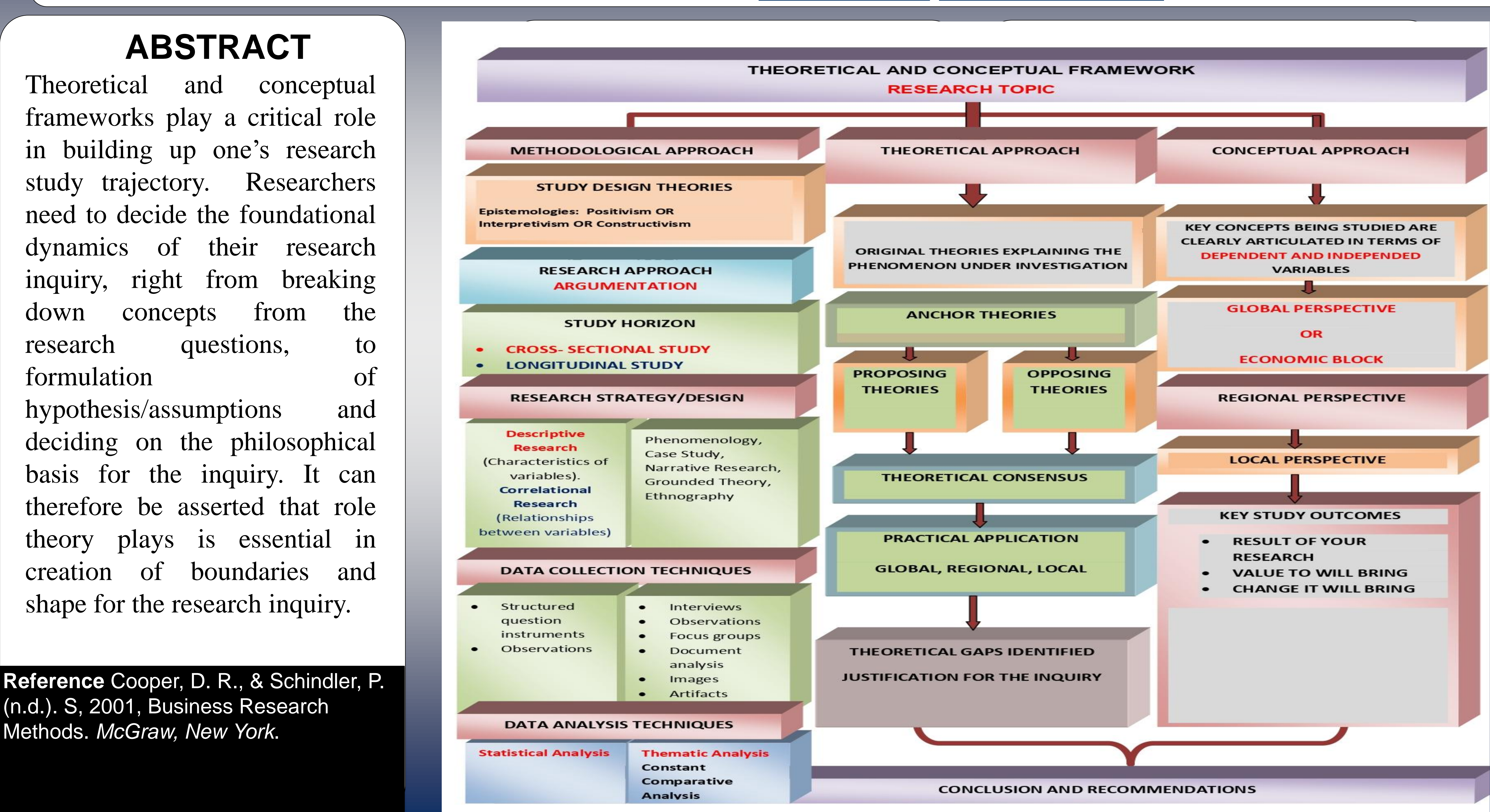

\section{RATIONALE}

The C.O.S.T.A. Framework provides a pertinent and structured pathway for an orderly investigative approach, which further supports conclusions that theories provide explanations for decisions made in the process of inquiry. These include methodological decisions, theoretical and conceptual decisions.

Therefore, it should always be understood that concepts are ideas that are structured. These ideas then inform the way reality is explicated from different paradigmic perspectives. This statement demonstrates intergration of concepts and theory and then theoretical and conceptual frameworks.

Reference Aldrich, H. E., \& Martinez, M. A. (2007). Many are called, but few are chosen: An evolutionary perspective for the study of entrepreneurship. In Entrepreneurship (pp 293-311). Springer. 